\title{
Expert Delphi survey on research and development into drugs for neglected diseases
}

Angela Fehr ${ }^{1}$, Petra Thürmann ${ }^{2}$ and Oliver Razum ${ }^{1 *}$

\begin{abstract}
Background: Tropical infectious diseases are called neglected, because they are, inter alia, characterized by an R\&D deficit. A similar deficit exists for rare (orphan) diseases which neither promise a sufficient return on R\&D investment. To encourage the development of treatments for rare diseases, orphan drug acts were created which contain financial and non-financial incentives for the pharmaceutical industry. Similar instruments aimed exclusively at neglected diseases do not yet exist. Proposals for a regulatory approach to promote R\&D for neglected diseases include the application of selected orphan drug incentives, or the implementation of a Medical Research and Development Treaty (MRDT) with national funding obligations for medical R\&D. We compiled and analyzed experts' opinions on causes for the treatment deficit for neglected diseases and on desirable and feasible measures to promote neglected disease R\&D. Hereby, the focus was on mechanisms contained in orphan drug regulations and in the Medical Research and Development Treaty draft (Discussion draft 4, 2005). Lastly, we solicited experts' opinions on the desirability and feasibility of a regulatory instrument to foster R\&D for neglected diseases.
\end{abstract}

Methods: An international online-Delphi survey was conducted with 117 (first round) and 56 (second round) experts of different professional backgrounds and professional affiliations who formulated and ranked causes and solutions related to the treatment deficit for neglected diseases.

Results: In both rounds of survey, the majority of the participating experts (88.4\% first round, $86.8 \%$ second round) advocated the development of a regulatory instrument to promote R\&D for neglected diseases. Most experts (77.9\% first round, $79.3 \%$ second round) also considered this to be a feasible option. With the exception of market exclusivity, which was viewed critically, key provisions contained in orphan drug regulations were judged favorably also for neglected diseases. A majority ( $87.1 \%$ first round, $77.2 \%$ second round) supported national funding obligations for neglected diseases which are proposed by the Medical Research and Development Treaty draft.

Conclusions: While not all features of orphan drug regulations and of the MRDT draft received equal support, the view was expressed that a regulatory instrument would be a desirable and feasible measure to promote R\&D for neglected diseases.

\section{Background}

About one billion people worldwide suffer from so-called neglected diseases (NDs). Neglected diseases are a heterogeneous [1] group of predominantly, but not exclusively, tropical infectious diseases, such as Buruli ulcer, Blinding Trachoma, Dengue and Dengue Hemorrhagic Fever, Lymphatic Filariasis, Human African Trypanosomiasis, Onchocerciasis, or Schistosomiasis (a list of 15 NDs is available on http://www.who.int/neglected_diseases/diseases/en/).

\footnotetext{
* Correspondence: oliver.razum@uni-bielefeld.de

'Dept. of Epidemiology \& International Public Health, School of Public Health, Bielefeld University, P.O. Box 1001 31, 33501 Bielefeld, Germany Full list of author information is available at the end of the article
}

Common features of neglected diseases include their prevalence in poor populations in developing countries, their cause for stigma and discrimination, their high impact on morbidity and mortality and their relative neglect in terms of research and development activities. For some neglected diseases, tools are available to control, prevent or possibly eliminate them. For other so-called tool-deficient diseases, such tools are still lacking [2,3]. With their often chronic and crippling character, neglected diseases cause immense suffering for the individual patient. Their accumulated prevalence puts a severe strain on the affected societies, with serious and long-lasting social and economic adverse effects on the endemic regions [3]. Substandard living

\section{Biomed Central}

(c) 2011 Fehr et al; licensee BioMed Central Ltd. This is an Open Access article distributed under the terms of the Creative Commons Attribution License (http://creativecommons.org/licenses/by/2.0), which permits unrestricted use, distribution, and reproduction in any medium, provided the original work is properly cited. 
conditions, lack of clean water, sanitary facilities and access to health care contribute to their spread and persistence. Poverty, equivalent to the absence of purchasing power, is considered the main cause for the structural deficit that exists for drug R\&D into neglected diseases [2,4-12]. The World Health Organization (WHO) therefore not only speaks of neglected diseases, but also of "neglected populations" [13]. Owing to the lack of a market perspective for pharmaceutical products, R\&D efforts for neglected diseases are not proportionate to the diseases' prevalence and their public health impact $[14,15]$. A similar R\&D deficit exists for rare diseases whose small patient populations neither promise adequate returns on investment [16-19]. Public health policy responded to the treatment deficit for rare diseases with the adoption of orphan drug acts, i.e. regulatory instruments with financial and non-financial incentives for the pharmaceutical industry. Comparable legislation focusing on neglected diseases does not yet exist, even though tropical infectious diseases had originally been included both in the concept of "drugs of limited commercial value" [20] which formed the basis for the U.S. Orphan Drug Act, and in early drafts for the European legislation [21]. The first Orphan Drug Act (ODA) was adopted in 1983 in the United States [22], followed by similar legislation in Australia, Japan and, in the year 2000, in the European Union [23]. One incentive of orphan drug legislation is several years of market exclusivity for orphan products. Additionally, sponsors of designated orphan products benefit from fee waivers, protocol assistance and, under the U.S. Orphan Drug Act, from grants and tax credits.

The perceived commonality of rare and neglected diseases, i.e. structural R\&D deficits, has nourished a longstanding debate whether orphan drug incentives may also benefit neglected diseases. Owing to their reliance on market exclusivity, however, along with liberty of pricing, orphan drug acts have often been considered ineffective or inappropriate for neglected diseases [21,24-26].

A different regulatory approach to promote $R \& D$ for neglected diseases is included in the Medical Research and Development Treaty draft [27]. This document, which was submitted to the WHO Commission on Intellectual Property, Innovation and Public Health (CIPIH) in February 2005 [28], does not exclusively address R\&D for neglected diseases; instead, it aims to restructure funding for medical research and development entirely, whereby diseases of poverty are given particular attention. Proceeding from the notion that the current system of funding for medical R\&D, based on patents and high drug prices to recoup investment, is ineffective, expensive and does not respond to public health needs [28], the authors and sponsors of the Treaty propose national funding obligations for medical R\&D based on GDP or per capita income [27].
Both orphan drug-style incentives and the proposed Medical Research and Development Treaty continue to occupy a prominent place in the debate on promoting R\&D into neglected diseases [26,29]. Therefore, we considered it timely and of relevant public health interest to explore among experts the desirability and feasibility of a regulatory instrument and of a selection of mechanisms and incentives contained therein.

\section{Methods}

The survey was based on the concept of a Policy Delphi. A Policy Delphi aims to solicit as many different views on an issue as possible to provide decision makers with the broad spectrum of aspects that have to be considered in a decision-making process [30]. To this end, it follows the characteristic Delphi process of anonymous rounds of survey with feedbacks after each round. A Policy Delphi usually involves three to five rounds, with extensive analyses of dissensions. Guidelines for its implementation recommend i.a. at least two professionals to design/ monitor the exercise, sometimes prior development of scenarios, factual summaries of background information, pre-tests, presenting respondents their original vote, as well as ensuring that the panel represents a peer group. As Turoff predicts for Policy Delphis, where "the respondents feel strongly about the issues, and this should be the case, $[\ldots]$ ", "[...] the questionnaire for the second round will be five to ten times that of the first round.", acknowledging that the items that were contributed later do not receive the same treatment as those listed from the beginning of the survey [30]. We designed the survey based on these guidelines, yet limited the number of rounds to two, with utmost effort devoted to the analysis of suggestions received between the rounds. The questionnaire for the first round was pretested and the initial invitation to participate in the survey was accompanied by a brief project description. The respondents were not shown their votes from previous rounds, though, as this would have required that their anonymity vis-à-vis the research team is lifted; we decided to maintain anonymity as we had stated.

A literature search and document analysis preceded the design of the questionnaire for the first round of survey. Five individuals of different academic backgrounds pretested the first questionnaire and contributed 21 technical and editorial comments. 530 potential participants were initially identified of whom we attempted to contact 388 experts. The following sources were used to compile the panel of experts:

- Publications on neglected and orphan diseases

- Participants in the Conference on Neglected Infectious Diseases, organized by the DG Research of the European Commission, Brussels, November 8 and 9, 
2006, which AF attended http://ec.europa.eu/research/ health/infectious-diseases/neglected-diseases/pdf/nidconference-final-report052007_en.pdf

- Contributions to two online hearings (November 1-15, 2006 and August 15 - September 30, 2007) of the WHO Intergovernmental Working Group (WHO-IGWG) to develop a global strategy and plan of action for neglected diseases http://www.who.int/ phi/public_hearings/en/

- A letter signed by 162 scientists, public health experts, lawyers, economists, government representatives and parliamentarians to accompany the submission of the Medical Research and Development Treaty draft to the WHO Commission on Intellectual Property, Innovation and Public Health in 2005.

The survey was conducted online in two rounds (March 8-April 3, 2008 and July 10-August 15, 2008; see Additional File 1 Additional File 2: Questionnaires Round I and Round II) using Globalpark EFS Survey 5.2 [31]. In total, the questionnaires contained seven (six in the second round) closed-ended questions, nine full-text fields for items to be added to the questionnaire, one closed-ended question with three options for reply, two hybrid questions and three (six in the second round) fulltext fields for general comments. In a qualitative analysis [32] between the first and the second round, full-text suggestions were structured and grouped into categories from which new items were developed and incorporated into the second-round questionnaire. Feedbacks, a key feature of the Delphi process [33], consisted of graphic illustrations of frequency analyses and of pdf-documents with the contents of the nine full-text fields and the three comment sections; both were integrated into the questionnaire for the second round and could be accessed via links. Following the second and last round of the survey, the experts received a link to the survey software to view frequency distributions and comments of the second round. This final feedback closed the exercise. The panel was anonymous so that the replies could not be attributed to the survey participants. For reasons of anonymity, intraindividual variations in the respondents replies between the first and the second round of survey were not tracked. Statistical analyses were performed using Microsoft Excel and SPSS for tabular and graphic presentation.

\section{Results}

\section{Participation, attrition, demographic data}

Of the 388 experts whom we attempted to contact, 159 experts initially agreed to participate in the first round of the survey; of these, 117 fully completed the first questionnaire, and 56 the first and the second questionnaire. Professional backgrounds of the experts in both rounds were in medicine $(36.4 \% / 32.1 \%)$, public health $(30.5 \% /$ $26.85 \%)$, biology/biomedical sciences $(30.4 \%$, only round two), pharmaceutical sciences (17.9\%, only round two), law $(8.5 \% / 10.7 \%)$, political science $(7.6 \% / 12.5 \%)$, economy ( $4.2 \% / 0 \%)$, veterinary medicine $(1.8 \%$, only round two $)$ and 'other' (33.1\%/8.9\%). Multiple responses were possible; biology/biomedical sciences, pharmaceutical sciences and veterinary medicine were added in the second round based on full-text details given in the "other"-field during the first round.

Data on professional affiliations of the experts for both rounds revealed affiliations with academia (53.6\%/ $54.7 \%)$, industry $(10.7 \% / 11.3 \%)$, international organizations $(4.5 \% / 7.5 \%)$, national governments/parliaments (5.4\%/7.5\%), non-governmental organizations (14.3\%/ $11.3 \%)$, public private partnerships $(3.8 \%$, only round two) and 'other' (11.6\%/3.8\%). The category 'public private partnership' was added in the second round following full-text entries in the first round. Based on publically available data for the 388 experts we initially attempted to contact, we presumed that $48.2 \%(n=187)$ were from academia, $17.5 \%(n=68)$ from national governments/parliaments), $13.9 \%$ from non-governmental organizations, $8.5 \%(\mathrm{n}=33)$ from industry, $8.3 \%(\mathrm{n}=$ 32) from backgrounds we were unable to specify ('other'), as well as $3.6 \%(\mathrm{n}=14)$ from international organizations. Of the participants in both rounds, $74.8 \%$ (75.5\%) indicated their place of residency in a developed country, $18.9 \%(20.8 \%)$ in a developing country, and $6.3 \%(3.8 \%)$ in a threshold country/emerging market.

To benefit from answers by experts who abandoned the questionnaire during the course of the survey, frequency distributions were based on $\mathrm{N}=159$ for the first and $\mathrm{N}=77$ for the second round, with valid $\mathrm{n}$ calculated for each questionnaire item.

\section{Causes for the treatment deficit for neglected diseases}

The first chapter in both rounds of survey dealt with the importance of likely causes for the treatment deficit for neglected diseases. In the first round, seven causes, retrieved from literature search and document analysis were listed; following the experts' suggestions for additional items, the list was expanded to 15 items in the second round (Table 1).

The experts were rather agreed on the importance of the causes, whereby in the first round of survey both public and private funding deficits were rated slightly more important than the lack of access to existing drugs, inadequate $R \& D$ infrastructure in endemic countries or the absence of effective drugs. In the second round of survey, two newly-added causes, labeled 'poverty as a disease-proliferating factor' and 'poverty as the reason for market failure', were considered the most important causes for the treatment deficit; nearly equal importance 
Table 1 Causes for the treatment deficit for neglected diseases: Round I and II

\begin{tabular}{|c|c|c|c|c|c|c|c|c|}
\hline & & $\%(n)$ & $\%(n)$ & $\%(n)$ & $\%(n)$ & $\%(n)$ & & \\
\hline & & $\begin{array}{c}\text { most } \\
\text { important }\end{array}$ & important & unimportant & $\begin{array}{l}\text { least } \\
\text { important }\end{array}$ & $\begin{array}{c}\text { no } \\
\text { judgment }\end{array}$ & $\begin{array}{l}\text { Total valid } \\
\%(n)\end{array}$ & $\begin{array}{r}\text { Total N } \\
\text { (Missing) }\end{array}$ \\
\hline \multirow[t]{2}{*}{ No or insufficient sustainability of public funding for R\&D for neglected diseases } & $\begin{array}{c}\text { Round } \\
\text { । }\end{array}$ & $40,3 \%(48)$ & $\begin{array}{c}47,9 \% \\
(57)\end{array}$ & $7,6 \%(9)$ & $0,8 \%(1)$ & $3,4 \%(4)$ & $\begin{array}{c}100,0 \% \\
(119)\end{array}$ & $159(40)$ \\
\hline & $\begin{array}{l}\text { Round } \\
\text { II }\end{array}$ & $54,1 \%(33)$ & $\begin{array}{l}41,0 \% \\
(25)\end{array}$ & $3,3 \%(2)$ & $1,6 \%(1)$ & $0,0 \%(0)$ & $100 \%(61)$ & $77(16)$ \\
\hline \multirow[t]{2}{*}{$\begin{array}{l}\text { No or inadequate direct public funding for research and development (R\&D) for neglected } \\
\text { diseases }\end{array}$} & $\begin{array}{l}\text { Round } \\
\quad\end{array}$ & $35,2 \%(44)$ & $\begin{array}{c}60,0 \% \\
(75)\end{array}$ & $3,2 \%(4)$ & $0,0 \%(0)$ & $1,6 \%(2)$ & $\begin{array}{l}100,0 \% \\
(125)\end{array}$ & $159(34)$ \\
\hline & $\underset{\|}{\text { Round }}$ & $54,8 \%(34)$ & $\begin{array}{c}40,3 \% \\
(25)\end{array}$ & $4,8 \%(3)$ & $0,0 \%(0)$ & $0,0 \%(0)$ & $100 \%(62)$ & $77(15)$ \\
\hline \multirow[t]{2}{*}{ No or inadequate incentives for the private sector to invest into R\&D for neglected diseases } & $\begin{array}{c}\text { Round } \\
\text { I }\end{array}$ & $33,9 \%(42)$ & $\begin{array}{c}49,2 \% \\
(61)\end{array}$ & $8,9 \%(11)$ & $4,8 \%(6)$ & $3,2 \%(4)$ & $\begin{array}{l}100,0 \% \\
(124)\end{array}$ & $159(35)$ \\
\hline & $\begin{array}{c}\text { Round } \\
\text { II }\end{array}$ & $41,9 \%(26)$ & $\begin{array}{c}45,2 \% \\
(28)\end{array}$ & $8,1 \%(5)$ & $3,2 \%(2)$ & $1,6 \%(1)$ & $100 \%(62)$ & $77(15)$ \\
\hline \multirow[t]{2}{*}{ No or inadequate private sector investment into R\&D for neglected diseases } & $\begin{array}{c}\text { Round } \\
\mid\end{array}$ & $33,6 \%(42)$ & $\begin{array}{c}58,4 \% \\
(73)\end{array}$ & $4,8 \%(6)$ & $0,8 \%(1)$ & $2,4 \%(3)$ & $\begin{array}{c}100,0 \% \\
(125)\end{array}$ & $159(34)$ \\
\hline & $\begin{array}{c}\text { Round } \\
\text { II }\end{array}$ & $45,2 \%(28)$ & $\begin{array}{c}40,3 \% \\
(25)\end{array}$ & $4,8 \%(3)$ & $8,1 \%(5)$ & $1,6 \%(1)$ & $100 \%(62)$ & $77(15)$ \\
\hline \multirow[t]{2}{*}{ No or inadequate access to effective drugs for neglected diseases } & $\begin{array}{c}\text { Round } \\
\text { । }\end{array}$ & $33,1 \%(40)$ & $\begin{array}{c}47,1 \% \\
(57)\end{array}$ & $9,1 \%(11)$ & $8,3 \%(10)$ & $2,5 \%(3)$ & $\begin{array}{c}100,0 \% \\
(121)\end{array}$ & $159(38)$ \\
\hline & $\begin{array}{c}\text { Round } \\
\text { II }\end{array}$ & $41,0 \%(25)$ & $\begin{array}{c}47,5 \% \\
(29)\end{array}$ & $4,9 \%(3)$ & $6,6 \%(4)$ & $0,0 \%(0)$ & $100 \%(61)$ & $77(16)$ \\
\hline \multirow[t]{2}{*}{ No or inadequate research infrastructure in countries with neglected diseases } & $\begin{array}{c}\text { Round } \\
\text { । }\end{array}$ & $29,5 \%(36)$ & $\begin{array}{c}55,7 \% \\
(68)\end{array}$ & $7,4 \%(9)$ & $6,6 \%(8)$ & $0,8 \%(1)$ & $\begin{array}{c}100,0 \% \\
(122)\end{array}$ & $159(37)$ \\
\hline & $\begin{array}{c}\text { Round } \\
\text { II }\end{array}$ & $27,9 \%(17)$ & $\begin{array}{c}60,7 \% \\
(37)\end{array}$ & $8,2 \%(5)$ & $3,3 \%(2)$ & $0,0 \%(0)$ & $100 \%(61)$ & $77(16)$ \\
\hline \multirow[t]{2}{*}{ No or ineffective drugs for neglected diseases } & $\begin{array}{c}\text { Round } \\
\text { । }\end{array}$ & $20,5 \%(24)$ & $\begin{array}{c}48,7 \% \\
(57)\end{array}$ & $15,4 \%(18)$ & $8,5 \%(10)$ & $6,8 \%(8)$ & $\begin{array}{c}100,0 \% \\
(117)\end{array}$ & $159(42)$ \\
\hline & $\begin{array}{c}\text { Round } \\
\text { II }\end{array}$ & $30,0 \%(18)$ & $\begin{array}{c}58,3 \% \\
(35)\end{array}$ & $8,3 \%(5)$ & $3,3 \%(2)$ & $0,0 \%(0)$ & $100 \%(60)$ & $77(17)$ \\
\hline Disease-specific research difficulties (unknown etiology, lack of research material) & $\begin{array}{c}\text { Round } \\
\text { II }\end{array}$ & $4,9 \%(3)$ & $\begin{array}{c}62,3 \% \\
(38)\end{array}$ & $18,0 \%(11)$ & $11,5 \%(7)$ & $3,3 \%(2)$ & $100 \%(61)$ & $77(16)$ \\
\hline No or inadequate research coordination & $\begin{array}{c}\text { Round } \\
\text { II }\end{array}$ & $8,2 \%(5)$ & $\begin{array}{c}49,2 \% \\
(30)\end{array}$ & $32,8 \%(20)$ & $6,6 \%(4)$ & $3,3 \%(2)$ & $100 \%(61)$ & $77(16)$ \\
\hline Lack of awareness/visibility of neglected diseases & $\begin{array}{c}\text { Round } \\
\text { II }\end{array}$ & $32,8 \%(20)$ & $\begin{array}{c}52,5 \% \\
(32)\end{array}$ & $13,1 \%(8)$ & $1,6 \%(1)$ & $0,0 \%(0)$ & $100 \%(61)$ & $77(16)$ \\
\hline Lack of health-needs driven priority setting in public funding & $\begin{array}{c}\text { Round } \\
\text { II }\end{array}$ & $44,3 \%(27)$ & $\begin{array}{c}50,8 \% \\
(31)\end{array}$ & $4,9 \%(3)$ & $0,0 \%(0)$ & $0,0 \%(0)$ & $100 \%(61)$ & $77(16)$ \\
\hline No or inadequate health delivery infrastructure and staff in developing countries & $\begin{array}{c}\text { Round } \\
\text { II }\end{array}$ & $45,9 \%(28)$ & $\begin{array}{c}41,0 \% \\
(25)\end{array}$ & $9,8 \%(6)$ & $1,6 \%(1)$ & $1,6 \%(1)$ & $100 \%(61)$ & $77(16)$ \\
\hline
\end{tabular}


Table 1 Causes for the treatment deficit for neglected diseases: Round I and II (Continued)

\begin{tabular}{|c|c|c|c|c|c|c|c|c|}
\hline Inadequate research priorities in private sector $R \& D$ & $\begin{array}{c}\text { Round } \\
\text { II }\end{array}$ & $48,4 \%(30)$ & $\begin{array}{c}37,1 \% \\
(23)\end{array}$ & $11,3 \%(7)$ & $3,2 \%(2)$ & $0,0 \%(0)$ & $100 \%(62)$ & $77(15)$ \\
\hline Poverty as reason for market failure (perception of no market for drugs, insufficient R\&D) & $\begin{array}{c}\text { Round } \\
\text { II }\end{array}$ & $55,0 \%(33)$ & $\begin{array}{c}35,0 \% \\
(21)\end{array}$ & $5,0 \%(3)$ & $3,3 \%(2)$ & $1,7 \%(1)$ & $100 \%(60)$ & $77(17)$ \\
\hline $\begin{array}{l}\text { Poverty as disease-proliferating factor (i.a. inadequate prevention, inadequate housing, lack of } \\
\text { clean water) in endemic countries }\end{array}$ & $\begin{array}{c}\text { Round } \\
\text { II }\end{array}$ & $57,4 \%(35)$ & $\begin{array}{c}32,8 \% \\
(20)\end{array}$ & $6,6 \%(4)$ & $3,3 \%(2)$ & $0,0 \%(0)$ & $100 \%(61)$ & $77(16)$ \\
\hline
\end{tabular}

The results for those items that were added to the second round of survey are shown in the lower part of the table 
was attributed to the lack of (sustainable) public R\&D funding, which had been ranked first in the initial round of survey. 13 of the 15 causes listed in the second round were considered most important or important by more than $80 \%$ of the panelists; only two items, i.e. diseasespecific research difficulties and no or inadequate research coordination received less than $80 \%$ of aggregated positive replies.

\section{Orphan drug regulations for rare diseases}

The first question in this section, which asked if and to which extent the respondents were familiar with orphan drug laws, served as a filter question. Experts with no knowledge about these laws $(n=53)$ skipped the question on their effectiveness, while those with active $(\mathrm{n}=$ 13 ) and with passive knowledge $(n=60)$ continued to the assessment. $61.4 \%$ of the respondents rated orphan drug regulations very effective or effective; of their individual incentives, market exclusivity was given the highest ranking $(22.1 \%)$ in the category "very effective"; the highest aggregated positive reply (very effective/effective) was given to tax credits (62.3\%). (Table 2)

\section{Measures to promote R\&D for neglected diseases}

In the next chapter of the questionnaire, the participating experts were requested to rank (according to desirability and feasibility) a list of possible measures to promote $R \& D$ for neglected diseases. Three key incentives contained in orphan drug regulations, i.e. tax credits, fee waivers and protocol assistance, or scientific advice, were considered desirable and feasible to foster R\&D for neglected diseases by more than two thirds of the experts in both rounds. (Table 3, Table 4)

National funding obligations for medical R\&D and prize funds proposed in the Medical Research and Development Treaty draft were supported by a majority of experts in both rounds; the concept of separating innovation incentives from drug prices rendered slightly more controversial results. Perhaps owing to the farreaching character of these paradigm changes, the survey participants were slightly cautious in predicting their feasibility. (Table 5, Table 6)

In the first round of survey, we received 134 proposals for modifications of previously listed measures or for additional measures. These covered funding priorities, research cooperation, capacity building and knowledge transfer, access, visibility and awareness, incentives, and structural reforms and regulations. After careful analysis, the proposals were developed into a list of 50 measures for the second round of survey.

\section{A regulatory instrument to promote $R \& D$ for neglected diseases}

Further to the questions on causes and measures, it was of interest to learn whether the panelists considered it desirable and feasible to have a regulatory instrument to promote $R \& D$ for neglected diseases in which these measures might be absorbed. In both rounds of survey, the respondents found the option (very) desirable as well as feasible. (Table 7)

Cross-tabulations by professional affiliation on the basis of aggregated positive replies (very desirable/desirable) revealed that, in the first round of survey, most subgroups were supportive of the concept of a regulatory instrument (90\% academia, 100\% national government/ parliament, $100 \%$ international organizations, $93.8 \%$ nongovernmental organizations and $100 \%$ "other") Of the experts affiliated with industry, $58.3 \%$ expressed a positive opinion on a regulatory instrument, while $41.6 \%$ said it was undesirable or very undesirable. In the second round of survey, experts with affiliations in academia, national government/parliament, non-governmental organization and other affiliations again gave over $90 \%$ of support for a regulatory instrument. Opinions in the subgroup "industry" remained diverse $(66.7 \%$ for and $33.3 \%$ against a regulatory instrument). Also, representatives of international organizations were less agreed in the second round; one representative considered it desirable, one undesirable and two expressed no judgment. Similarly, the two experts affiliated with a public private partnership were disagreed on the subject.

In both rounds of survey, the feasibility of a regulatory instrument was judged positively by experts from academia $(80 \% / 85.7 \%)$, national governments/parliaments $(83.3 \% / 100 \%)$ and from NGOs $(87.6 \% / 83.3 \%)$ In contrast, while $80 \%$ of the respondents affiliated with an international organization had considered a regulatory instrument to be a feasible option in the first round, three out of four experts in this subgroup said it was possibly unfeasible in the second round. Experts

Table 2 Effectiveness of orphan drug laws and incentives

\begin{tabular}{|c|c|c|c|c|c|}
\hline & very effective & effective & ineffective & very ineffective & no judgment \\
\hline Orphan drug laws & $7.1 \%$ & $54.3 \%$ & $17.1 \%$ & $0 \%$ & $21.4 \%$ \\
\hline Market exclusivity & $22.1 \%$ & $33.8 \%$ & $17.6 \%$ & $4.4 \%$ & $22.1 \%$ \\
\hline Tax credits & $14.5 \%$ & $47.8 \%$ & $10.1 \%$ & $1.4 \%$ & $26.1 \%$ \\
\hline Protocol assistance & $13.2 \%$ & $41.2 \%$ & $14.7 \%$ & $0 \%$ & $30.9 \%$ \\
\hline Fee reduction/Fee waivers & $8.8 \%$ & $41.2 \%$ & $23.5 \%$ & $1.5 \%$ & $25.0 \%$ \\
\hline
\end{tabular}


Table 3 Desirability of orphan drug incentives for neglected diseases

\begin{tabular}{|c|c|c|c|c|c|c|c|c|}
\hline & & $\%(n)$ & $\%(n)$ & $\%(n)$ & $\%(n)$ & $\%(n)$ & & \\
\hline & & very desirable & desirable & undesirable & very undesirable & no judgment & Total valid \% (n) & Total N (Missing) \\
\hline \multirow[t]{2}{*}{ Market exclusivity } & Round I & $7,8 \%(9)$ & $19,1 \%(22)$ & $26,1 \%(30)$ & $20,9 \%(24)$ & $26,1 \%(30)$ & $100 \%(115)$ & $159(44)$ \\
\hline & Round II & $3,6 \%(2)$ & $20,0 \%(11)$ & $36,4 \%(20)$ & $21,8 \%(12)$ & $18,2 \%(10)$ & $100 \%(55)$ & $77(22)$ \\
\hline \multirow[t]{2}{*}{ Tax credits } & Round I & $14,2 \%(16)$ & $48,7 \%(55)$ & $6,2 \%(7)$ & $1,8 \%(2)$ & $29,2 \%(33)$ & $100 \%(113)$ & $159(46)$ \\
\hline & Round II & $20,4 \%(11)$ & $46,3 \%(25)$ & $11,1 \%(6)$ & $3,7 \%(2)$ & $18,5 \%(10)$ & $100 \%(54)$ & $77(23)$ \\
\hline \multirow[t]{2}{*}{ Protocol assistance } & Round I & $25,9 \%(30)$ & $44,0 \%(51)$ & $4,3 \%(5)$ & $0,0 \%(0)$ & $25,9 \%(30)$ & $100 \%(116)$ & $159(43)$ \\
\hline & Round II & $33,9 \%(19)$ & $55,4 \%(31)$ & $3,6 \%(2)$ & $0,0 \%(0)$ & $7,1 \%(4)$ & $100 \%(56)$ & $77(21)$ \\
\hline \multirow[t]{2}{*}{ Fee reduction/Fee waivers (e.g. for marketing approval, scientific advice) } & Round I & $27,0 \%(31)$ & $53,9 \%(62)$ & $3,5 \%(4)$ & $0,9 \%(1)$ & $14,8 \%(17)$ & $100 \%(115)$ & 159 (44) \\
\hline & Round II & $28,1 \%(16)$ & $56,1 \%(32)$ & $7,0 \%(4)$ & $0,0 \%(0)$ & $8,8 \%(5)$ & $100 \%(57)$ & $77(20)$ \\
\hline
\end{tabular}


Table 4 Feasibility of orphan drug incentives for neglected diseases

\begin{tabular}{|c|c|c|c|c|c|c|c|c|}
\hline & & $\%(n)$ & $\%(n)$ & $\%(n)$ & $\%(n)$ & $\%(n)$ & & \\
\hline & & $\begin{array}{l}\text { very (definitely) } \\
\text { feasible }\end{array}$ & feasible & unfeasible & $\begin{array}{l}\text { definitely } \\
\text { unfeasible }\end{array}$ & $\begin{array}{c}\text { no } \\
\text { judgment }\end{array}$ & $\begin{array}{l}\text { Total valid \% } \\
\text { (n) }\end{array}$ & $\begin{array}{r}\text { Total N } \\
\text { (Missing) }\end{array}$ \\
\hline \multirow[t]{2}{*}{ Market exclusivity } & $\begin{array}{c}\text { Round } \\
\quad\end{array}$ & $10 \%(11)$ & $\begin{array}{l}28,2 \% \\
(31)\end{array}$ & $\begin{array}{c}20,9 \% \\
(23)\end{array}$ & $2,7 \%(3)$ & $38,2 \%(42)$ & 110 & $159(49)$ \\
\hline & $\begin{array}{c}\text { Round } \\
\text { II }\end{array}$ & $13.7 \%(7)$ & $\begin{array}{c}27.5 \% \\
(14)\end{array}$ & $27.5 \%(14)$ & $2.0 \%(1)$ & $29.4 \%(15)$ & 51 & $77(26)$ \\
\hline \multirow[t]{2}{*}{ Tax credits } & $\begin{array}{c}\text { Round } \\
\quad\end{array}$ & $21.8 \%(24)$ & $\begin{array}{c}40,0 \% \\
(44)\end{array}$ & $4,5 \%(5)$ & $2,7 \%(3)$ & $30,9 \%(34)$ & 110 & $159(49)$ \\
\hline & $\underset{\|}{\text { Round }}$ & $35.3 \%(18)$ & $\begin{array}{c}37.3 \% \\
(19)\end{array}$ & $5.9 \%(3)$ & $2.0(1)$ & $19.6 \%(10)$ & 51 & $77(26)$ \\
\hline \multirow[t]{2}{*}{ Protocol assistance } & $\begin{array}{c}\text { Round } \\
\quad\end{array}$ & $32.7 \%(36)$ & $\begin{array}{c}44,5 \% \\
(49)\end{array}$ & $1.8 \%(2)$ & $0,0 \%(0)$ & $20.9 \%(23)$ & 110 & $159(50)$ \\
\hline & $\underset{\text { Round }}{\text { II }}$ & $35,3 \%(18)$ & $\begin{array}{c}52.9 \% \\
(27)\end{array}$ & $3.9 \%(2)$ & $0.0 \%(0)$ & $7.8 \%(4)$ & 51 & $77(26)$ \\
\hline \multirow[t]{2}{*}{$\begin{array}{l}\text { Fee reduction/Fee waivers (e.g. for marketing approval, scientific } \\
\text { advice) }\end{array}$} & $\begin{array}{c}\text { Round } \\
\quad\end{array}$ & $26,6 \%(29)$ & $\begin{array}{c}51.4 \% \\
(56)\end{array}$ & $4.6 \%(5)$ & $0,9 \%(1)$ & $16.5 \%(18)$ & 110 & $159(49)$ \\
\hline & $\begin{array}{c}\text { Round } \\
\text { /I }\end{array}$ & $23.1 \%(12)$ & $\begin{array}{c}50.0 \% \\
(26)\end{array}$ & $11.5 \%(6)$ & $0.0 \%(0)$ & $15.4 \%(8)$ & 52 & $77(25)$ \\
\hline
\end{tabular}


Table 5 Desirability of MRDT proposals to promote R\&D for neglected diseases

\begin{tabular}{|c|c|c|c|c|c|c|c|c|}
\hline & & $\%(n)$ & $\%(n)$ & $\%(n)$ & $\%(n)$ & $\%(n)$ & & \\
\hline & & very desirable & desirable & undesirable & very undesirable & no judgment & Total valid \% (n) & Total N (Missing) \\
\hline \multirow[t]{2}{*}{ Prize funds with prizes awarded based on degree of innovation } & Round I & $35.6 \%(42)$ & $44.1 \%(52)$ & $6.8 \%(8)$ & $3.4 \%(4)$ & $10.2 \%(12)$ & 118 & $159(41)$ \\
\hline & Round II & $33.9 \%(19)$ & $35.7 \%(20)$ & $12.5 \%(7)$ & $3.6 \%(2)$ & $14.3 \%(8)$ & 56 & $77(21)$ \\
\hline \multirow[t]{2}{*}{ Obligation for national governments to invest into neglected disease R\&D } & Round I & $48.3 \%(56)$ & $38.8 \%(45)$ & $6.9 \%(8)$ & $1.7 \%(2)$ & $4.3 \%(5)$ & 116 & $159(43)$ \\
\hline & Round II & $40.4 \%(23)$ & $36.8 \%(21)$ & $14.0 \%(8)$ & $1.8 \%(1)$ & $7.0 \%(4)$ & 57 & $77(20)$ \\
\hline \multirow[t]{2}{*}{ Separation of innovation incentives from drug prices } & Round I & $38.8 \%(45)$ & $30.2 \%(35)$ & $4.3 \%(5)$ & $4.3 \%(5)$ & $22.4 \%(26)$ & 116 & $159(43)$ \\
\hline & Round II & $38.2 \%(21)$ & $27.3 \%(15)$ & $12.7 \%(7)$ & $5.5 \%(3)$ & $16.4 \%(9)$ & 55 & $77(22)$ \\
\hline
\end{tabular}


Table 6 Feasibility of MRDT proposals to promote R\&D for neglected diseases

\begin{tabular}{|c|c|c|c|c|c|c|c|c|}
\hline & & $\%(n)$ & $\%(n)$ & $\%(n)$ & $\%(n)$ & $\%(n)$ & & \\
\hline & & definitely feasible & feasible & unfeasible & definitely unfeasible & no judgment & Total valid \% (n) & Total N \\
\hline \multirow[t]{2}{*}{ Prize funds with prizes awarded based on degree of innovation } & Round I & $20.9 \%(23)$ & $60.0 \%(23)$ & $4.5 \%(5)$ & $0.9 \%(1)$ & $13.6 \%(15)$ & 110 & 159 \\
\hline & Round II & $30.8 \%(16)$ & $48.1 \%(25)$ & $11.5 \%(6)$ & $1.9 \%(1)$ & $7.7 \%(4)$ & 52 & $77(25)$ \\
\hline \multirow[t]{2}{*}{ Obligation for national governments to invest into neglected disease R\&D } & Round I & $28.2 \%(31)$ & $41.8 \%(46)$ & $20.0 \%(22)$ & $5.5 \%(6)$ & $4.5 \%(5)$ & 110 & $159(49)$ \\
\hline & Round II & $11.3 \%(6)$ & $43.4 \%(23)$ & $35.8 \%(19)$ & $3.8 \%(2)$ & $5.7 \%(3)$ & 53 & $77(24)$ \\
\hline \multirow[t]{2}{*}{ Separation of innovation incentives from drug prices } & Round I & $12.6 \%(14)$ & $39.6 \%(44)$ & $11.7 \%(13)$ & $6.3 \%(7)$ & $29.7 \%(33)$ & 111 & $159(48)$ \\
\hline & Round II & $15.1 \%(8)$ & $41.5 \%(22)$ & $11.3 \%(6)$ & $9.4 \%(5)$ & $22.6 \%(12)$ & 53 & $77(24)$ \\
\hline
\end{tabular}


Table 7 A regulatory instrument to promote R\&D for neglected diseases: Round I and II

\begin{tabular}{|c|c|c|c|c|c|c|c|c|}
\hline & very desirable & desirable & undesirable & very undesirable & no judgment & $\mathrm{n}=$ & missing** & Median*** \\
\hline Desirability* & $44.2 \%(49.1 \%)$ & $44.2 \%(37.7 \%)$ & $7.1 \%(3.8 \%)$ & $1.8 \%(3.8 \%)$ & $2.7 \%(5.7 \%)$ & $113(53)$ & $\begin{array}{c}46 \\
(24)\end{array}$ & $2.00(1.00)$ \\
\hline & very (definitely) feasible & feasible & unfeasible & definitely unfeasible & no judgment & $n$ & missing** & Median*** \\
\hline Feasibility* & $14.2 \%(18.9 \%)$ & $63.7 \%(60.4 \%)$ & $8.0 \%(15.1 \%)$ & $3.5 \%(5.7 \%)$ & $10.6 \%(0.0 \%)$ & $113(53)$ & $\begin{array}{c}46 \\
(24)\end{array}$ & $2.00(2.00)$ \\
\hline
\end{tabular}

Results of the second round of the survey are shown in brackets

${ }^{*} 1$ = very desirable/very (definitely) feasible, $2=$ desirable/feasible, $3=$ undesirable/unfeasible, $4=$ very undesirable/definitely unfeasible, $5=$ no judgment

**Participants who abandoned the questionnaire prior to this question or who did not answer the question

*** Excludes $5=$ no judgment

affiliated with industry were equally skeptical in their assessment of the instrument's feasibility (50\%/66.7\%).

\section{Discussion}

Method

The Delphi method and its online implementation were well received. A large number of experts participated in the survey over a period of five months. They devoted time and effort to fill out two online questionnaires and contributed new items as well as extensive - also critical! comments. The latter ranged from "not sure what you can deduce from this listing - most listed items are clearly important, and there's much overlap, so what are we going to learn from "important" versus "very important"?" to "The results will [be] interesting and helpful for policy development" or: "Very interesting and useful. I guess sometimes one would like more nuanced options for a more appropriate answer".

As we have shown in the first paragraph of the Results section, the sample was not balanced in terms of professional backgrounds, professional affiliations or the place of residence. The aim of the survey was to gather as broad a spectrum of perspectives as possible. The sample selection was purposive insofar as we chose specific sources from which to gather a panel of interested experts, such as relevant publications, conferences, hearings etc.. Prior to the first round of the survey, we could only assume the distribution of experts in the demographic categories. Since it was impossible to predict participation and attrition rates at the onset of the study, we did not attempt to reduce and adjust the initial panel to represent a balanced sample. We do not dare to anticipate how and if the results of the study may have differed if the panel had been more balanced. However, we observed variations within groups in cross-tabulations which suggest that the assessments made by the experts may not necessarily be linked to professional affiliations.

\section{Results}

The survey facilitated the quantification and correlation of views far beyond what can be reproduced in this paper. Its outcome underlined that insufficient funding for R\&D for neglected diseases is one of the most important causes for the treatment deficit. Yet it is by no means the only important cause: there was only one item (no/ineffective drugs for NDs) in the first round, and two items (no/inadequate research coordination and diseasespecific research difficulties) in the second round that received less than $80 \%$ of aggregated positive responses (most important/important) by all participating experts. Similarly, while respondents from all professional affiliations chose funding issues as most important in the first round, they suggested 98 additional items, which formed the basis for the extension of the list of causes in the second round. Consequently, funding issues became one of several causes that received high priority in the different professional affiliations. This process and its outcome underline the complexity of the issue and the need to uphold multifocal strategies that will increase awareness, reduce poverty, adjust $R \& D$ priorities to include NDs, increase and sustain public and private sector funding, and promote health as well as research infrastructure in endemic countries.

Certainly, no single mechanism or regulatory instrument can cover this broad range of challenges. The participants of the survey offered a diversity of comments on the desirability and feasibility of a regulatory instrument, including: "This is a purely national decision unlikely to be easily introduced into legislative bodies, but definitely worth trying. Once a few countries install some such instrument others will follow."; "would best be done under the auspices of the WHO, would cover all aspects from discovery to delivery, with follow up monitoring"; "We have too much regulation already and implementation on a global basis is simply not practicable".

Various modifications to orphan drug laws for the benefit of NDs have been suggested in recent years such as transferable market exclusivity $[34,35]$, or the definition of all NDs as orphan diseases [25]. The survey revealed that incentives such as tax credits, fee waivers and protocol assistance were also considered promising to promote $R \& D$ into drugs for neglected diseases. In view of the fact that a majority of the respondents advocated a regulatory instrument to promote R\&D for neglected diseases, it 
may be of interest to further explore whether it would be beneficial to extend selected orphan drug incentives to neglected diseases [36]. Correspondingly, for several years, the concept of a biomedical R\&D treaty has been debated at international levels [26,28,29,37-39], and discussed in the scientific community [34,40-46]. One of its key concepts, i.e. national funding obligations for medical $R \& D$, was considered desirable by a majority of the survey participants. The feasibility of this proposal, however, was judged more cautiously.

The respondents were not asked, however, to assess orphan drug acts or the MRDT for neglected diseases as such. This, on the one hand, precludes a comprehensive answer to the question of their desirability and feasibility for ND research and development. On the other hand, the separation of individual measures from specific regulatory instruments was part of the survey's concept to enable us to learn which measures are attractive and practicable in the eyes of the respondents. It may thus be of interest to carry forward, expand and focus the research, perhaps with a similar methodology, to engage experts and stakeholders in determining which measures could contribute to a future instrument to promote R\&D for neglected diseases.

\section{Conclusions}

The treatment deficit for neglected diseases can neither be attributed to a single cause, nor can it be remedied by a single measure. Both orphan drug acts and the MRDT are controversial approaches to promoting neglected disease $R \& D$. The ongoing debate on the two concepts points to a strong interest in a regulatory instrument, which we could confirm in our Delphi survey. Such instrument may not rely on the same incentives as orphan drug regulations, or completely restructure medical $R \& D$ funding as proposed in the MRDT. Still, if it included mechanisms to provide sufficient and sustainable funding for effective, affordable and field-sensitive diagnostics and treatments, facilitated research cooperation and increased awareness for NDs on health policy agendas, it would express the same political will to guarantee equitable health care for patients with neglected diseases as orphan drug regulations intended for patients with rare diseases.

It is recommended that a Policy Delphi is followed by a working group which may utilize the results to formulate relevant policy recommendations. [30] The data which have been gathered in the survey will be analyzed further so that the valuable input of the respondents will contribute to the ongoing search for mechanisms to promote R\&D for neglected diseases.

\section{Additional material}

Additional file 1: Questionnaire Round I. Questionnaire of the first round of the Delphi survey.
Additional file 2: Questionnaire Round II. Questionnaire of the second round of the Delphi survey.

\section{Acknowledgements}

The authors wish to sincerely thank all participants in the Delphi survey for the time and effort they took to complete the questionnaires. Without their valuable contributions, this project would not have come into being. We acknowledge support of the publication fee by Deutsche

Forschungsgemeinschaft and the Open Access Publication Funds of Bielefeld University.

\section{Author details}

${ }^{1}$ Dept. of Epidemiology \& International Public Health, School of Public Health, Bielefeld University, P.O. Box 1001 31, 33501 Bielefeld, Germany. ${ }^{2}$ University of Witten/Herdecke, Philipp Klee-Institute for Clinical

Pharmacology, HELIOS Klinikum Wuppertal, Wuppertal, Germany.

\section{Authors' contributions}

AF, PT and OR conceived of the survey, and participated in its design and coordination. AF implemented the survey and performed the statistical analysis. AF, PT and OR drafted, read and approved the manuscript.

\section{Competing interests}

The authors declare that they have no competing interests.

Received: 21 March 2011 Accepted: 16 November 2011 Published: 16 November 2011

\section{References}

1. Aagaard-Hansen J, Chaignat CL: Neglected tropical diseases: equity and social determinants. In Equity, social determinants and public health programmes. Edited by: Blas, Erik, Kurup, Anand Sivasankara. WHO; 2010: [http://www.who.int/neglected_diseases/Social_determinants_NTD.pdf].

2. WHO, Carter Center: Integrated control of the neglected tropical diseases. A neglected opportunity ripe for action. Paper jointly prepared by WHO and the Carter Center, presented to the Global Health and the United Nations meeting.Carter Center, Atlanta, Georgia, USA 2008 [http://www.who.int/ neglected_diseases/NTD_integrated_control.pdf].

3. WHO: Working to overcome the global impact of neglected tropical diseases. First WHO report on neglected tropical diseases 2010 [http:// whqlibdoc.who.int/publications/2010/9789241564090_eng.pdf].

4. Molyneux DH: "Neglected" diseases but unrecognised successeschallenges and opportunities for infectious disease control. Lancet 2004, 364(9431):380-383, PM:15276399.

5. Pécoul B: Government action needed to step up research and development for world's most neglected diseases. Expert Rev Anti Infect Ther 2005, 3(6):841-843, PM:16307495.

6. Moran M, Guzman J, Henderson K, Ropars A-L, McDonald A, McSherry L, et al: Neglected Disease Research \& Development: New Times, New Trends. G-Finder 2009 Sidney/London, The George Institute for International Health. G-Finder; 2009.

7. Trouiller $P$, Torreele E, Olliaro $P$, White N, Foster $S$, Wirth D, et al: Drugs for neglected diseases: a failure of the market and a public health failure? Trop Med Int Health 2001, 6(11):945-951, PM:11703850.

8. Moran M, Guzman J, Ropars AL, McDonald A, Jameson N, Omune B, et al: Neglected disease research and development: how much are we really spending? PLOS Med 2009, 6(2):e30, PM:19192946.

9. Anderson G: Spurring new research for neglected diseases. Health Aff (Millwood) 2009, 28(6):1750-1759, PM:19887416.

10. Herrling P: Patent sense. Nature 2007, 449(7159):174-175, PM:17851514.

11. Hopkins AL, Witty MJ, Nwaka S: Mission possible. Nature 2007, 449(7159):166-169, PM:17851512.

12. Moran M, Guzman J, Henderson K, Abela-Oversteegen L, Wu L, Omune B, et al: G-Finder 2010. Global Funding of Innovation for Neglected Diseases. Neglected disease research and development: Is the Global Financial Crisis Changing R\&D? Policy Cures. London International Development Centre 2011. 
13. WHO: Neglected Tropical Diseases. Hidden successes, Emerging Opportunities. WHO/CDS/NTD/2006.2 2006 [http://whqlibdoc.who.int/hq/ 2006/WHO_CDS_NTD_2006.2_eng.pdf].

14. Trouiller P, Olliaro P, Torreele E, Orbinski J, Laing R, Ford N: Drug development for neglected diseases: a deficient market and a publichealth policy failure. Lancet 2002, 359(9324):2188-2194, PM:12090998.

15. Pécoul B: New drugs for neglected diseases: from pipeline to patients. PLoS Med 2004, 1(1):e6, PM:15526054.

16. Aymé $S$, Schmidtke J: Networking for rare diseases: a necessity for Europe. Bundesgesundheitsblatt-Gesundheitsforschung-Gesundheitsschutz 2007, 12:1477-1483.

17. Denis A, Simoens S, Fostier C, Mergaert L, Cleemput I: Policies for Orphan Diseases and Orphan Drugs. Health Technology Assessment (HTA). KCE reports 112C (D/2009/10.273/32) Brussels, Belgian Health Care Knowledge Centre (KCE); 2009

18. Haffner ME, Whitley J, Moses M: Two decades of orphan product development. Nat Rev Drug Discov 2002, 1(10):821-825, PM:12360259.

19. Wetterauer B, Schuster R: Seltene Krankheiten. Probleme, Stand und Entwicklung der nationalen und europopäischen Forschungsförderung. Bundesgesundheitsbl-Gesundheitsforsch-Gesundheitsschutz 2008, 51:519-528.

20. Interagency Task Force to the Secretary of Health EaW: Interagency Task Force Report on Significant Drugs of Limited Commercial Value. 1979 [http://rarediseases.info.nih.gov/files/1979_Interagency_Task_Force_Report_ on_Significant_Drugs_of_Limited_Clinical_Value.pdf].

21. Milne C, Kaitin K, Ronchi E: Orphan Drug Laws in Europe and the US: Incentives for the Research and Development of Medicines for the Diseases of Poverty. WHO Commission on Macroeconomics and Health. CMH Working Paper Series, Paper No. WG2: 82001.

22. United States Congress: The Orphan Drug Act (as amended). Code of Federal Regulations, Title 21, Revised as of April 1, 2004 1983, 5: [http://www. fda.gov/orphan/oda.htm].

23. OrphaNet: Worldwide Comparison of Regulation 2010 [http://www.orpha. net].

24. Trouiller $P$, Battistella C, Pinel J, Pécoul B: Is orphan drug status beneficial to tropical disease control? Comparison of the American and future European orphan drug acts. Trop Med Int Health 1999, 4(6):412-420, PM:10444316.

25. Villa S, Compagni A, Reich MR: Orphan drug legislation: lessons for neglected tropical diseases. Int J Health Plann Manage 2009, 24(1):27-42, PM:18435430.

26. WHO: Public health, innovation and intellectual property rights. Report of the Commission on Intellectual Property Rights, Innovation and Public Health 2006 [http://www.who.int/intellectualproperty/documents/thereport/ ENPublicHealthReport.pdf].

27. CPTech: Medical Research and Development Treaty (MRDT). Discussion draft 42005 [http://www.cptech.org/workingdrafts/rndtreaty4.pdf].

28. CPTech: CPTech Letter concerning "Request to Evaluate Proposal for New Global Medical R\&D Treaty" 2005 [http:/www.who.int/intellectualproperty/ submissions/CPTech.pdf].

29. WHO: Research and Development. Coordination and Financing. Report of the Expert Working Group Geneva, World Health Organization 2010 [http:// www.who.int/phi/documents/RDFinancingEN.pdf].

30. Turoff M: The Policy Delphi. In The Delphi Method: Techniques and Applications Edited by: Linstone, Harold A, Turoff, Murray 2002 [http://is.njit. edu/pubs/delphibook/].

31. Globalpark: Globalpark Enterprise Feedback Suite 5.2. EFS Survey. Version 1.12007.

32. Beywl W, Schepp-Winter E: Zielgeführte Evaluation von Programmen - ein Leitfaden. QS Materialien zur Qualitätssicherung in der Kinder- und Jugendhilfe. Heft 29 Bundesministerium für Familie, Senioren, Frauen und Jugend: Bonn; 2000 [http://www.univation.org/download/QS_29.pdf].

33. Häder M: Delphi Befragungen. Ein Arbeitsbuch. Wiesbaden, Westdeutscher Verlag GmbH; 2002.

34. Tren R, Bate R: Government-Controlled Pharmaceutical Research and Development: A Recipe for Desaster. American Enterprise Institute for Public Policy Research 2006 [http://www.aei.org/files/2006/05/22/ 20060522_HPOPOSTED_g.pdf].

35. Grabowski HG: Increasing R\&D incentives for neglected diseases: Lessons from the Orphan Drug Act. In International Public Goods and Transfer of Technology under a Globalized Intellectual Property Regimen. Edited by: Maskus, Keith E, Reichman, Jerome H. Cambridge University Press; 2005:
36. Fehr A, Thurmann P, Razum O: Editorial: drug development for neglected diseases: a public health challenge. Trop Med Int Health 2006, 11(9):1335-1338, PM:16930253.

37. WHO: Macroeconomics and Health: Investing in Health for Economic Development. Report of the Commission on Macroeconomics and Health 2001 [http://www.cid.harvard.edu/archive/cmh/cmhreport.pdf].

38. WHO: Global strategy and plan of action on public health, innovation and intellectual property. WHA61.21 2008.

39. Proposal by Bangladesh, Barbados, Bolivia and Suriname. Proposal for WHO Discussions on a Biomedical R\&D Treaty 2009.

40. Dentico N, Ford $N$ : The courage to change the rules: a proposal for an essential health R\&D treaty. PLOS Med 2005, 2(2):e14, PM:15736991.

41. DiMasi J, Grabowski H: Patens and R\&D Incentives: comments on the Hubbard and Love Trade Framework for Financing Pharmaceutical R\&D. Submission to the WHO Commission on Intellectual Property, Innovation and Public Health 2004 [http://www.who.int/intellectualproperty/news/en/ Submission3.pdf].

42. Farlow A: A Global Medical Research and Development Treaty. An answer to global health needs? IPN Working Papers on Intellectual Property, Innovation and Health 2007 [http://www.policynetwork.net/sites/default/ files/Global_Medical_Research_web.pdf].

43. Hubbard T, Love J: A new trade framework for global healthcare R\&D. PLoS Biol 2004, 2(2):E52, PM:14966544.

44. Hubbard T: Reply to the comments requested by CIPIH and WHO to the CPTech proposal for a Medical Research and Development Treaty (MRDT). 2005 [http://www.who.int/intellectualproperty/submissions/ SubmissionsHubbard.pdf].

45. Orsenigo L: Review of CPTech Proposal for an R\&D Treaty. Submission to the WHO Commission on Intellectual Property, Innovation and Public Health 2005 [http://www.who.int/intellectualproperty/submissions/ orsenigo_comments.pdf].

46. Winters DJ: Expanding global research and development for neglected diseases. Bull World Health Organ 2006, 84(5):414-416, PM:16710555.

\section{Pre-publication history}

The pre-publication history for this paper can be accessed here: http://www.biomedcentral.com/1472-6963/11/312/prepub

doi:10.1186/1472-6963-11-312

Cite this article as: Fehr et al.: Expert Delphi survey on research and development into drugs for neglected diseases. BMC Health Services Research 2011 11:312.

\section{Submit your next manuscript to BioMed Central and take full advantage of:}

- Convenient online submission

- Thorough peer review

- No space constraints or color figure charges

- Immediate publication on acceptance

- Inclusion in PubMed, CAS, Scopus and Google Scholar

- Research which is freely available for redistribution

Submit your manuscript at www.biomedcentral.com/submit
C Biomed Central 